The Israeli Journal of Aquaculture - Bamidgeh, IJA_69.2017.1377, 7 pages

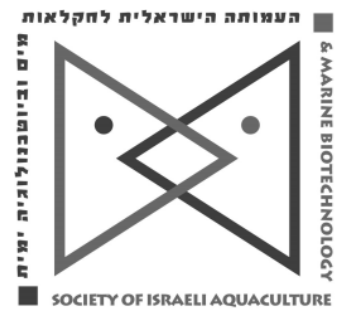

The IJA appears exclusively as a peer-reviewed on-line open-access journal at http://www.siamb.org.il. To read papers free of charge, please register online at registration form.

Sale of $I J A$ papers is strictly forbidden.

\title{
Formation of Pinocytic Activity in Cultured Common Dentex (Dentex dentex) Larvae Intestine
}

\section{Tülay Akayli ${ }^{1 *}$, Melike Erkan $^{2}$, Özgür Çanak ${ }^{1}$, Çiğdem Ürkü ${ }^{1}$}

\author{
${ }^{1}$ Istanbul University, Faculty of Fisheries, Department of Aquaculture, \\ Ordu Cad. No:8 34134 Laleli / Istanbul, Turkey. \\ 2 Istanbul University, Faculty of Biology, Department of Zoology, 34134, \\ Vezneciler / Istanbul Turkey
}

Keywords: Dentex dentex; electron microscopy; fish larvae; fish nutrition; pinocytic activity

\begin{abstract}
Larval fish have a relatively poorly developed immune system and hence they primarily rely on non-specific immune responses produced in the skin and gut. This study aims to illustrate the fine structure of gut development in common dentex (Dentex dentex) larvae and determine the initiation of pinocytic activity, which is an important early non-specific immune response in fish intestines, during various live-food feeding stages (yeast enriched rotifer, Artemia nauplii and metanauplii) from hatching (D0) to 25 days after hatching (D25) by using transmission electron microscopy (TEM). A total of 54 larvae were sampled and examined with electron microscopy. The results show that hind-gut intestine enterocytes have morphological features which suggest they play a role in absorption and intracellular digestion of nutrients in fish. The presence of vigorous pinocytic activity in the Artemia feeding stage between 17-25 days after hatching is evidence for the development of a nonspecific immune system. In the present study, the ultrastructural gut development of cultured common dentex was investigated for the first time and the data reported in this study may provide additional fundamental knowledge for improving larval rearing success in common dentex culture.
\end{abstract}

* Corresponding author. Tülay Akaylı e-mail: takayli@yahoo.com 


\section{Introduction}

Common dentex (Dentex dentex L., 1758) is a promising candidate for Mediterranean and Turkish marine aquaculture due to its rapid growth and high reproductive rate (Abellan 2000). The most important problem with intensive rearing of this species is the possibility of high mortality rates at the larval and juvenile stages (Abellan 2000; Koumoundouros et al. 2004).

For food search, capture, absorption, and digestion, teleost fish larvae must develop efficient structures beginning from the hatching stage (Calzada et al. 1998; Carrassón et al. 2006, Jutfelt 2006). The fish intestine is a complex multifunctional organ which has an important role in metabolism, digestion, and feed absorption functions (Ringø et al. 2003; Jutfelt, 2006). The gut increases in length and width throughout the entire larval phase and thus its absorptive surface increases considerably (Moksness et al. 2004; Jutfelt 2006). Digestive enzymes and regional differentiation have been detected in gilthead sea bream larvae as evidence of developing mechanisms for absorption and digestion of exogenous food. This has been previously explained for other vertebrates (Calzada et al. 1998). Fish intestines are potential ports of entry for pathogenic bacteria such as vibrios (Grisez et al. 1996; Ring et al. 2003) and aeromonads (Ring et al. 2004). Hence, the gut immune system must prevent penetration and infection of the intestinal epithelium by these pathogens (Grisez et al. 1996; Gomez and Balcazar 2008).

Mammals are generally born at comparatively advanced stages of development unlike most fish, which hatch at an ontogenetically primitive stage. The immune defense systems of fish mature during development of eggs, and throughout the larval stages (Secombes and Ellis 2012; Moksness et al. 2004). Since larval fish have a relatively poorly developed immune system, they rely primarily on non-specific immune responses produced by the non-specific defence systems located in the skin and gut (Vine 2006; Secombes and Ellis 2012).

Endocytosis, which is an important mechanism of the non-specific immune system in fish, occurs by phagocytosis and pinocytosis (Dalmo et al. 1997). During phagocytosis, bacteria or other particulate matters are trapped, but in pinocytosis, cells engulf external substances, gathering them into special membrane-bound vesicles contained within the cell.

This process can be best observed by electron microscopy (LaBella and Krass 1973). Pinocytic activity of fish intestine against substances such as protein antigens has been investigated in sharpsnout seabream Diplodus puntazzo (Aktulun et al. 2008), common carp, Cyprinus carpio (Rombout et al. 1985), gilthead sea bream, Sparus aurata (Calzada et al. 1998), yellow catfish, Pelteobagrus fulvidraco (Yang et al. 2010), barramundi, Lates calcarifer (Walford and Lam 1993) and salmonids (Jutfelt 2006). For example, a high level of pinocytotic activity was detected in the rectal cells of 6 day old and 14 day old barramundi larvae indicating that protein macromolecules were being absorbed by these cells (Walford and Lam 1993). Besides the functional development, fish gut plays an important role in the formation of early non-specific immune defense mechanisms (Moksness et al. 2004; Secombes and Ellis 2012). Colonization of the sterile gut in hatching (Hansen and Olafsen 1999) generally increases at the onset of exogenous feeding, resembling the microflora of the live food (such as Artemia and Rotifer) as opposed to that of the surrounding environment (Muroga et al. 1987). Therefore, the intestinal microbiota of aquatic animals may change rapidly with the intrusion of microbes originating from water and food (Gatesoupe 2007).

Knowledge of gut development and initiation of endocytic activity is necessary to obtain the greatest benefits from feeds. The goal of the present study was to describe the fine structure and functional status of gut development in common dentex larvae during different feeding stages with yeast-enriched rotifers, Artemia nauplii, metanauplii and dry formulae diet from hatching (D0) to 25 days after hatching (D25). The goal was also to assess the timing of the beginning of endocytosis and pinocytosis and make a prediction for the amelioration of feeding regimes during the larval stages, hence increasing growth rate and survival in common dentex. 


\section{Materials and Methods}

Sampling procedures. Common dentex (Dentex dentex) larvae used in this study were cultured and reared in a commercial land-based fish farm (Akuvatur S.A., İzmir, Turkey) between 2009 and 2010. During the sampling period, this fish farm used its own standard larval culture procedures and followed its own standard feeding regime based on previous scientific research on the feeding of common dentex larvae (in ex. Santamaria et al. 2004) during the whole larval period; the larvae were fed 8-10 times daily with live feed at a total of $1 \%$ live weight (yeast enriched rotifer, Artemia nauplii, Artemia metanauplii) and dry formulae diet respectively. Common dentex larvae were kept in standard circular 2 ton fiberglass tanks in the hatchery with water temperature of $18-20^{\circ} \mathrm{C}$, salinity of $24 \%$, and $\mathrm{pH}$ of $7.9-8.0$.

A total of 54 larvae were sampled: two larvae samples were collected daily on D0 and D3; 12 larvae samples were collected daily on D5, D17 and D23; and 14 larval samples were collected on D25. They were brought alive, from the hatchery tanks to the laboratory and their wet weight was determined by microbalance (Muroga et al. 1987).

Electron microscopy. Two larval samples from D0 and D3 and eight larval samples collected previously were fixed in $0.2 \mathrm{M}$ sodium cacodylate buffer $(\mathrm{pH}=7)$ containing $2.5 \%$ glutaraldehyde and $3.5 \%$ sucrose at $4{ }^{\circ} \mathrm{C}$ for $2 \mathrm{~h}$. To maintain better infiltration of the fixative, caudal parts were completely removed before fixation of larvae sampled during D0-D5. Both head and caudal parts were removed in larvae samples from D17 under a dissection microscope. From D23 and D25, only $1 \mathrm{~mm}$ long sections of larvae samples from the intestinal region were fixed. After $2 \mathrm{~h}$ in glutaraldehyde, all specimens were fixed in $2 \%$ osmium tetroxide buffered with $0.2 \mathrm{M}$ sodium cacodylate for $2 \mathrm{~h}$ at $3^{\circ} \mathrm{C}$, dehydrated in an ethanol series followed by propylene oxide, and finally embedded in Epon. The specimens were then sectioned with an ultra-microtome (Leica), and treated with alcoholic uranyl acetate (Watson 1958) and lead citrate (Reynold 1963) for contrast. The sections obtained were examined at $60 \mathrm{kV}$ in a transmission electron microscope (TEM) (JEOL 100 CX II). All chemicals were of analytical grade.

\section{Results}

According to the microbalance weight measurements, common dentex larvae samples weighed $4 \mathrm{mg}$ (D0), $3.8 \mathrm{mg}$ (D3), $5 \mathrm{mg}$ (D5), $10 \mathrm{mg}$ (D17), $14 \mathrm{mg}$ (D23), and 16,7 mg (D25) respectively. Gut cells of common dentex larvae at hatching (D0), which feed on yolk sac, were quite undifferentiated and it was determined that the intestinal loop was not yet fully formed. Also at this stage, presumptive intestinal regions showed only slight ultrastructural differences. Until the yolk-sac is depleted, a decrease in the wet-weight of the larvae was observed on day 3 . The number of intestinal cells increased slightly despite presence of some nutritive elements in the yolk sac, with opening of mouth and anus which is regarded as the initiation point of exogenous feeding after D3. This was followed by rapid cell differentiation. The pace of cell differentiation was faster in hindgut cells than in mid-gut cells.

In five-day-old larvae fed with yeast-enriched rotifer, the number of microvilli increased in the hind-gut. The presence and adherence of protein-like structures and also formation of protein inclusion bodies were detected in the lumen of the intestine (Fig. 1a, b) and the size of the rough endoplasmic reticulum (RER) in hind-gut epithelial cells increased noticeably (Fig. 1a, b). RER canals in this region were extended for food storage, contained mainly protein molecules (Fig. 1a), and later these molecules were observed to be stored in vesicles full of dense material (Fig. 1b). Five days after hatching, exogenous materials were first observed in the lumen of newly formed intestines and absorbed by tight junctions established around the extended canals of RER and ribosomes (Fig. 1a, b). 


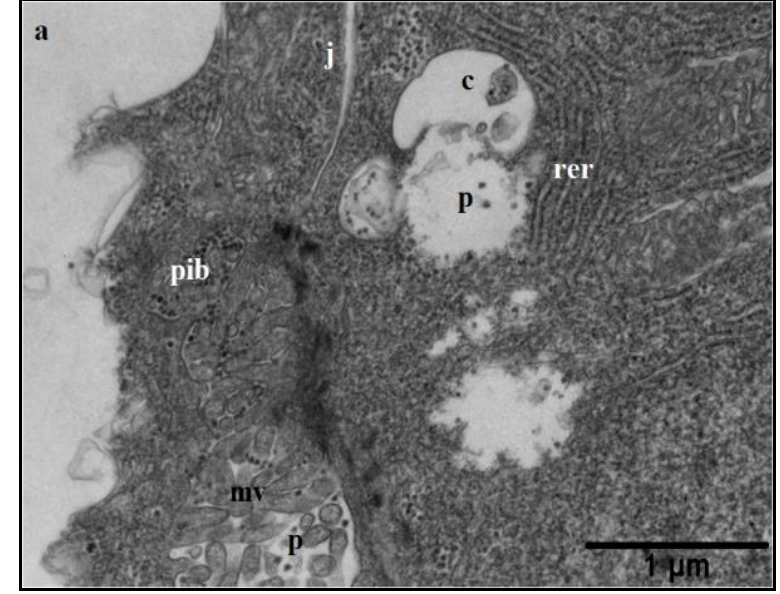

Fig. 1a Digestion of protein-like structures in the intestine of five-day-old larvae fed with rotifer. ( $p$ : protein-like structures, $m v$ : microvilli, j: tight junctions, $c$ : extended canals of RER, rer: rough endoplasmic reticulum)

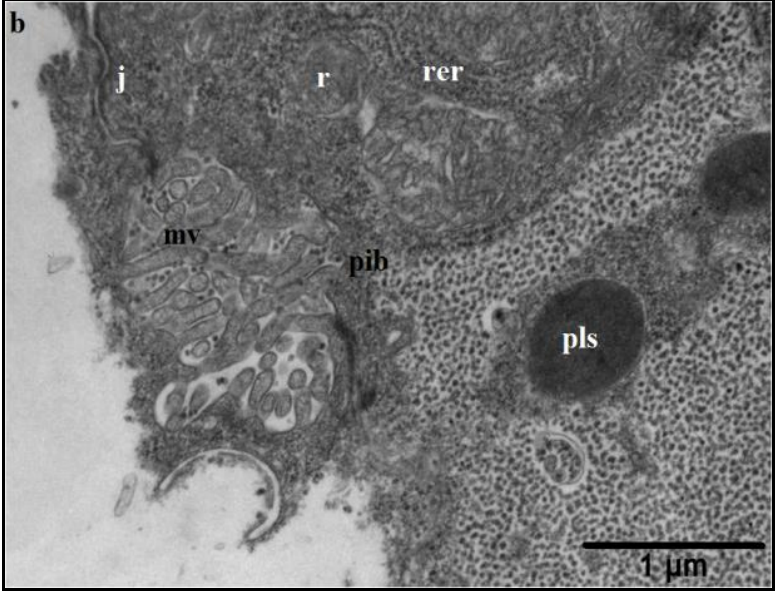

Fig. 1b Digestion of protein-like structures in the intestine of five-day-old larvae fed with rotifer. (mv: microvilli, pib: protein inclusion body, $\mathrm{j}$ : tight junctions, pls: cyst of protein-like structures, rer: rough endoplasmic reticulum, r: ribosome)

Parallel to larval development, a further increase in the size and number of microvilli at the apical side of the hindgut was observed at the Artemia nauplii feeding stage (D17). Initial pinocytic invaginations and vesicles on hind-gut epithelial cells were also observed at this stage (Fig. 2). In the 23 and 25 days old common dentex larvae fed with Artemia metanauplii, a continued increase in the number of microvilli was observed in the hindgut, pinocytic and endocytic enclosures became denser at this stage (Fig. 3), and the number of mitochondria (with various lengths from 0.5 up to $1.5 \mu \mathrm{m}$ ) under cell membranes also increased.

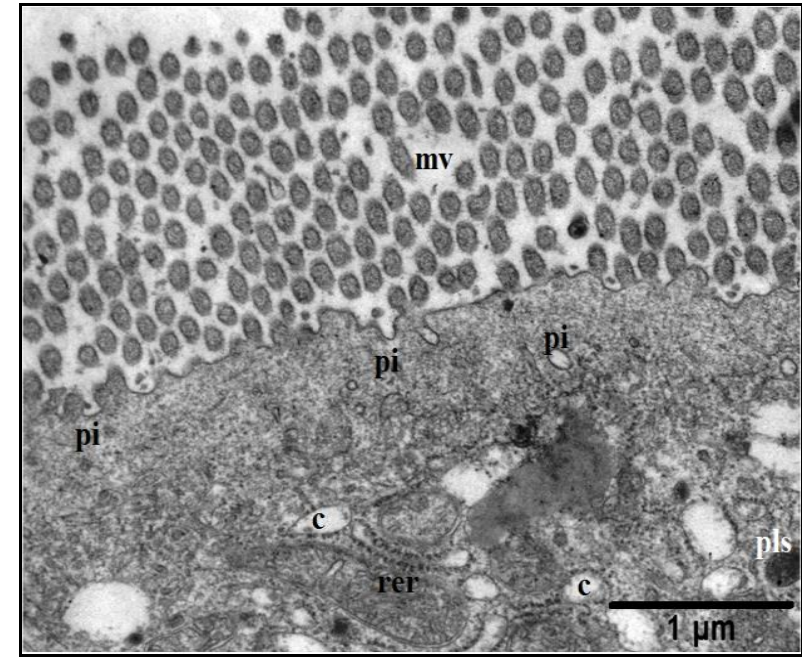

Fig. 2 The presence of pinocytotic invagination $(\mathrm{Pi})$ and extended RER canals in the midgut of 17-day-old larvae at the Artemia nauplii feeding stage. (mv: microvilli, pi: pinocytic invagination, rer: rough endoplasmic reticulum, c: extended canals of RER, pls: cyst of protein-like structures)

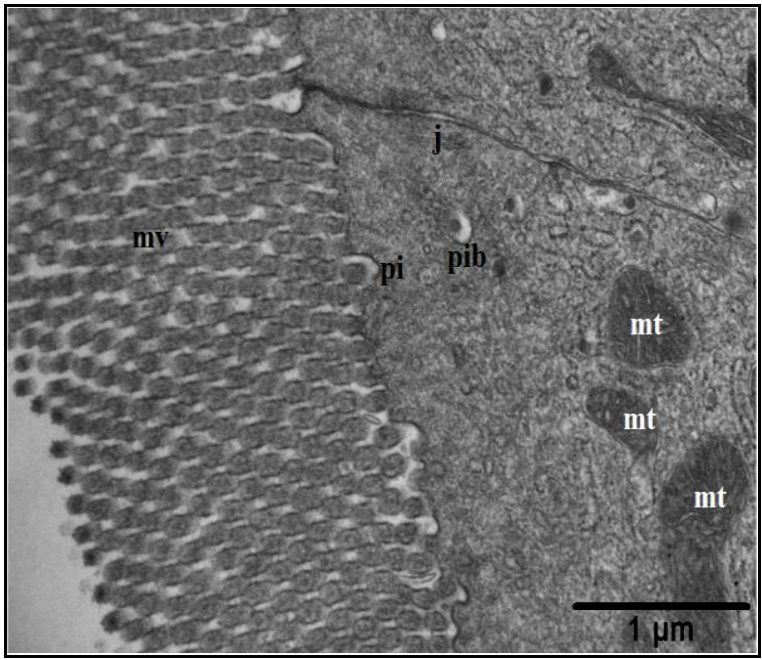

Fig. 3 Heavy pinocytosis observed in the midgut of 23- and 25-day-old larvae at the Artemia metanauplii feeding stage. (mv: microvilli, pi: pinocytic invagination, pib: protein inclusion body, mt: mitochondria, $\mathrm{j}$ : tight junction) 
Discussion

As fish larvae have a fairly underdeveloped immune system, their defense mechanisms rely primarily on non-specific immune responses created in the skin and gut (Moksness et al. 2004; Vine 2006; Secombes and Ellis 2012). A non-specific immune response process of endocytosis, which occurs via phagocytosis and pinocytosis, is important for the effectiveness of this system in the fish gut (Dalmo et al. 1997; Yang et al. 2010).

Common dentex, which is a strictly carnivorous fish species, has a relatively shorter digestive tract (especially intestine) with a large stomach and a low number of pyloric caeca (Santamaria et al. 2004) compared with the omnivorous species of the Sparidae family, Sparus aurata and Diplodus puntazzo (Carrason et al. 2006). Because of the shorter length of the intestine, strict differentiation of its regions (mid-gut and hind-gut) was relatively difficult to detect during morphological investigation, but with the electron microscopic study, they could be differentiated by ultrastructural imaging (Carrason et al., 2006).

Common dentex larvae feed on their yolk sac during the first three days after hatching. As the mouth opens after D3, first exogenous food sources are required (Santamaria et al. 2004). On day 6, endogenous and exogenous feeding is observed and their oil globule is resorbed on D9. At this stage live feed such as Artemia and Rotifer are crucial to satisfy the nutritional requirements of common dentex. During the Artemia feeding period, steatosis (fatty degeneration) was described as a common feature in common dentex and nutritional factors were reported to be the primary cause of mortality rather than infectious agents (Crespo et al. 2001). An increase in lipid droplets in yellow catfish posterior intestine after D3 were reported (Yang et al. 2010) but no such pathological disorders were detected in the present study.

Compared with European sea bass and gilt-head sea bream, common dentex has a shorter larval phase (Crespo et al. 2001; Koumoundouros et al. 2004; Santamaria et al. 2004). Similar to other fish species, we observed that the intestine of the common dentex larva develops rapidly after the beginning of exogenous feeding. As previously described in common dentex (Carrason et al. 2006) and gilthead sea bream (Elbal et al. 2004), gut cells of common dentex larvae at hatching (D0) were quite undifferentiated and presumptive intestinal regions showed only slight ultrastructural differences. In common dentex, until the anus and mouth are opened, the intestinal loop is not complete (Santamaria et al. 2004) and the intestinal regions are not yet differentiated in the first 2-3 days after hatching while feeding on yolk sac. As the yolk sac is depleted and exogenous feeding begins, the process of gut formation and regional differentiation is accelerated and an increase in the number of microvilli is observed in 5 day old larvae fed with yeast-enriched rotifer. Epithelial cells of the lumen were observed converting protein-like structures into protein inclusion bodies. The results of this study suggest that at hatching stage, the gut cells of common dentex are quite undifferentiated but slight ultrastructural differences can be distinguished between the presumptive intestinal regions. (Calzada et al. 1998; Elbal et al. 2004).

Fish intestines are able to absorb macromolecules such as protein and protein-like structures in the diet through mucosal absorption and pinocytosis (Georgopoulou et al. 1986; Teskeredzic et al. 1998). Exogenous proteins are first taken in as inclusion bodies through the intestine of larvae fed with rotifer (Calzada et al. 1998; Yang et al. 2010; Elbal et al. 2004). In the present study, a higher exogenous protein intake in the rotifer feeding stage was detected in common dentex when compared to gilt-head sea bream (Calzada et al. 1998) and (Elbal et al. 2004) As a result of yolk-sac absorption, a decrease in the wet weight of common dentex larvae was observed on D3 but larvae began to grow rapidly during the exogenous feeding stages. In addition to these morphological changes, undifferentiated intestines at hatching stage showed an increase in the number of cells, rapid cell differentiation upon the opening of mouth and anus, and beginning of exogeneous feeding on D5. This is may be evidence of first absorption of exogenous materials. Since absorption was also observed in the 5 day old fish larvae and pinocytosis initially occurred later in 17 day old larvae in this study.

Understanding this mechanism is important for health maintenance. Because intestinal absorption and digestion of macromolecules such as proteins and protein-like 
structures is the key to demonstrating immunologic development (Rombout et al. 1985; Georgopoulou et al. 1986). Pinocytosis was observed in younger larval fish intestine, another process of endocytosis (phagocytosis) was also observed at later stages of the larval phase during the granulated feeding stage and juvenile common dentex intestine (Akaylı et al. 2015).

At this stage, (after D5) exogenous materials were initially observed in the lumen of newly formed intestines, and absorbed by tight junctions established around the extended canals of RER and ribosomes, which suggests that they also participate in the initial immune defense function of the intestines. The development of the RER canal was also previously determined in S. aurata on day 5 (Elbal et al. 2004). The lateral tight junction complexes just beneath the microvilli in the 5 day old common dentex larvae described here were also observed in S. aurata larvae (Elbal et al., 2004).

Many endocytic vesicles contain electron-dense material and numerous intracytoplasmic filament bundles (Ringø et al. 2003). We also observed that the hindgut intestine enterocytes had morphological features, indicating that they played a role in the absorption and intracellular digestion of nutrients. The rotifer feeding stage includes relatively high feed intake and rapid intestine development, but this is a primary act occurring before pinocytosis. Correspondingly, mass pinocytosis activity began during the Artemia feeding stages in common dentex. Parallel to dense pinocytic activity and a high need for energy, the number of mitochondria under the cell membranes also showed a significant increase during the Artemia feeding stages.

Experimental larval organogenesis in common dentex was investigated histologically (Santamaria et al. 2004) and the whole digestive tract in adult specimens were investigated with electron microscopy techniques (Carrason et al. (2006). The present study investigated the ultrastructural gut development of cultured common dentex larvae under standard conditions of a commercial hatchery for the first time. In conclusion, the data reported in this study provide supplementary fundamental knowledge that can regulate a larval feeding regime and timing of the eventual use of probiotics in common dentex.

\section{Acknowledgments}

This study was supported by the Istanbul University Research Projects Foundation (Project \#2637). We would also like to thank the Akuvatur Fish Farming Company for supplying fish material and assisting during the study.

\section{References}

Abellan E., 2000. Culture of common dentex (Dentex dentex L.): Present knowledge, problems and perspectives. Recent advances in Mediterranean aquaculture finfish species diversification. Zaragoza: CIHEAM, Cahiers Options Mediterranean's, 47: 157-168 http://om.ciheam.org/om/pdf/c47/00600615.pdf.

Aktulun S., Suzer C., Kamaci H. O, Coban D., Saka S. and Firat K., 2008. Activity of the digestive protease, chymotrypsin, in larvae of the cultured sharpsnout sea. bream (Diplodus puntazzo). Isr. J. Aquacult.-Bamidgeh, 60(2): 82-88.

Akaylı T., Erkan M., Yardimci R.E., Çanak Ö. and Ç. Ürkü, 2015. Interaction of gut flora and bacterial pathogens of cultured common dentex (Dentex dentex). Isr. J. Aquacult.-Bamidgeh, 67: 1136, 6 pp.

Calzada A., Medina A. and M. L. Gonzalez de Canales, 1998. Fine structure of the intestine development in cultured sea bream larvae. J Fish Biol., 53: 340-365.

Carrassón M., Grau A., Dopazo L.R. and S. Crespo, 2006. A histological, histochemical and ultrastructural study of the digestive tract of Dentex dentex (Pisces, Sparidae). Histol Histopathol., 21: 579-593.

Crespo S., Mateoa M.M., Santamaria C.A.R., Sala R., Grau A. and E. Pastor, 2001. Histopathological observations during larval rearing of common dentex Dentex dentex L. Sparidae. Aquaculture 192:121-132.

Dalmo R.A., Ingebrigtsen K. and J. Bøgwald, 1997. Non-specific defence mechanisms in fish, with particular reference to the reticuloendothelial system (RES). $J$ Fish Dis., 20: 241-273. 
Elbal M.T., Garcia Hernandez M.P., Lozano M.T. and B. Agulleiro, 2004. Development of the digestive tract of gilthead sea bream (Sparus aurata L.). Light and electron microscopic studies. Aquaculture, 234: 215-238.

Gatesoupe F.J., 2007. Live yeasts in the gut: Natural occurrence, dietary introduction, and their effects on fish health and development. Aquaculture, 267:20-30.

Georgopoulou U., Sire M.F. and J. M., Vernier, 1986. Immunological demonstration of intestinal absorption and digestion of protein macromolecules in the trout (Salmo gairdneri). Cell Tissue Res., 245: 387-395.

Gomez G.D. and J.L. Balcazar, 2008. A review on the interactions between gut microbiota and innate immunity of fish. FEMS Immunol Med Microbiol J., 52:145-154.

Grisez L., Chair M., Sorgeloos P. and F. Ollevier, 1996. Mode of infection and spread of Vibrio anguillarum in turbot Scophthalmus maximus larvae after oral challenge through live feed. Dis Aquat Organ., 26: 181-187.

Hansen G.H. and J.A. Olafsen, 1999. Bacterial interactions in early life stages of marine cold water fish. Microbial Ecology, 38: 1-26.

Jutfelt F., 2006. The Intestinal Epithelium of Salmonids Transepithelial Transport, Barrier Function and Bacterial Interactions. PhD Thesis, University of Goteborg, Sweden. $73 \mathrm{pp}$.

Koumoundouros G., Carrillob J., Divanachc P. and M. Kentouri, 2004. The rearing of common dentex Dentex dentex (L.) during the hatchery and on-growing phases. Aquaculture, 240: 165-173.

LaBella F.S. and M. E. Krass, 1973. New Terminology for cellular ingestion and egestion. In: F.S. LaBella (ed). Pinocytosis, MSS Information Corporation.

Moksness E. 2004. Functional development of organ systems from hatching to metamorphosis. In: E. Moksness, E. Kjorsvik, Y. Olsen (eds). Culture of cold-water marine fish. Blackwell Publishing Ltd., Oxford UK.

Muroga K., Higashi M. and H. Keitoku, 1987. The isolation of intestinal microflora of farmed seabream (Pagrus major) and black seabream (Acanthopagrus schlegeli) at larval and juvenile stages. Aquaculture 65: 79-88.

Ringø E., Olsen R.E., Mayhew T.M. and R. Myklebust, 2003. Electron microscopy of the intestinal microflora of fish. Aquaculture, 227: 395-415.

Ringø E., Jutfelt F., Kanapathippillai P., Bakken Y., Sundell K., Glette J., Mayhew T.M., Myklebust R. and R. E. Olsen, 2004. Damaging effect of the fish pathogen Aeromonas salmonicida ssp. salmonicida on intestinal enterocytes of Atlantic salmon (Salmo salar L.). Cell and Tissue Research, 318(2): 305-311.

Rombout J.H., Lamers C.H., Helfrich M.H., Dekker A. and J. J. Taverne-Thiele, 1985. Uptake and transport of intact macromolecules in the intestinal epithelium of carp (Cyprinus carpio L.) and the possible immunological implications. Cell Tissue Res., 239(3): 519-30.

Santamaria C.A., Mateo M.M., Traveset R., Sala R., Grau A., Pastor E. and C. Sarasquete, 2004. Larval organogenesis in common dentex Dentex dentex L. (Sparidae): Histological and histochemical aspects. Aquaculture, 237: 207-228.

Secombes C.J. and A. E. Ellis, 2012. The Immunology of Teleost. In: R.J. Roberts (ed) Fish Patology. Wiley-Blackwell, UK.

Teskeredzic Z., Teskeredzic E., McLean E. and R. Ash, 1998. Intact protein absorption by the fish gut. Ribarstvo, 56(3): 91-100.

Vine N.G., Leukes W.D. and H. Kaiser, 2006. Probiotics in marine larviculture. FEMS Microbiol Rev., 30(3): 404-427.

Walford J. and T. J. Lam, 1993. Development of digestive tract and proteolytic enzyme activity in seabass (Lates calcarifer) larvae and juveniles. Aquaculture, 109: 187-205.

Watson M. L., 1958. Staining of tissue sections for electron microscopy with heavy metals II. application of solutions containing lead and barium. J Biophys Biochem Cytol., 4(6): 727-730.

Yang R., Xie C., Fan Q., Gao C. and L. Fang, 2010. Ontogeny of the digestive tract in yellow catfish Pelteobagrus fulvidraco larvae. Aquaculture, 302: 112-123 